\title{
Cabeçuda-II: um conjunto de amoladores-polidores evidenciado em Laguna, SC
}

\author{
Claudia Rodrigues-Carvalho * \\ Rita Scheel-Ybert * \\ $\mathrm{MaDu}$ Gaspar * \\ Gina Faraco Bianchini * \\ Daniela Magalhães Klokler * \\ Marcela Nogueira de Andrade ** \\ Diogo de Souza Borges*
}

\section{Introdução}

\begin{abstract}
moladores-polidores são marcas ou conjunto de marcas deixadas em rochas pela fabricação ou curadoria de objetos polidos. A maioria dos autores associa estes vestígios à fabricação de lâminas de machados de pedra (Tenório 2003), mas eles podem estar relacionados também a trabalho em ossos, dentes ou madeira (Tiburtius \& Bigarella 1953). Amoladores-polidores fixos (produzidos sobre afloramentos rochosos), além da função de preparar e manter artefatos, são elementos da paisagem. Podem ser tomados, também, como registros rupestres, intervenções humanas que portam em si mensagens e significados simbólicos. Os amoladores-polidores demarcam o espaço e, com os sítios que lhes são correlatos, configuram um ambiente domesticado, uma paisagem.

Um conjunto de amoladores-polidores foi evidenciado ao lado do Sambaqui de Cabeçuda, município de Laguna, entre as lagunas de Santo Antônio dos Anjos e Imaruí, litoral sul do esta-
\end{abstract}

(*) Museu Nacional da Universidade Federal do Rio de Janeiro. Programa de Pós-Graduação em Arqueologia. Rodriges-Carvalho<claudia@mn.ufrj.br>; Scheel-Ybert <scheelybert@mn.ufrj.br>; Gaspar<madugaspar@terra.com.br>; Bianchini<ginabianchini@ufrj.br>; Klokler

<dklokler@gmail.com>; Borges <diogborges@gmail.com> $\left({ }^{* *}\right)$ Museu Nacional da Universidade Federal do Rio de Janeiro. Curso de Especialização em Geologia do Quaternário. <marcelanandrade@gmail.com> do de Santa Catarina, na altura do km 315 da BR-101. O sítio, georreferenciado pelas coordenadas 0712503/6852151 UTM (zona 22J, datum WGS86), encontra-se a sudoeste do sambaqui, sobre um embasamento granítico de coloração rósea (Guerra 1950) que aflora na margem da Lagoa de Santo Antônio dos Anjos.

O Sambaqui de Cabeçuda, o primeiro sítio litorâneo de grandes dimensões sistematicamente escavado, foi estudado por Luiz de Castro Faria, pesquisador do Museu Nacional, na década de 1950 (Castro Faria 1952, 1955, 1959). Em decorrência de sua implantação na paisagem e monumentalidade associada ao ritual funerário, o sítio é um importante assentamento costeiro. Nele foi coletada uma das maiores coleções de remanescentes humanos pré-históricos litorâneos do país; o número mínimo de indivíduos exumados por Castro Faria foi estimado em 162 adultos e 83 juvenis (Mendonça de Souza 1991). Uma datação realizada por Castro Faria na época das escavações situa a ocupação em torno de $4.120 \pm 120$ AP.

As pesquisas no Sambaqui de Cabeçuda foram retomadas a partir de 2010, no quadro de uma iniciativa envolvendo o Museu Nacional/ UFRJ, o MAE/USP e o GRUPEP/UNISUL. Pesquisadores dessas instituições vêm conjugando ações, projetos e esforços para ampliar o entendimento deste sambaqui. Além dos amoladores-polidores, novos dados referentes ao ritual funerário e ao processo de formação do sítio demonstram o grande potencial informativo deste conjunto de sítios. Apesar de ter sofrido intensa 
destruição antrópica, o Sambaqui de Cabeçuda, assim como o sítio Cabeçuda-II, ainda guarda informações relevantes para a reconstrução do modo de vida de populações litorâneas.

\section{Resultados e discussão}

Ainda que dois pequenos sulcos de polimento já tivessem sido observados no local em campanhas de escavação anteriores deste projeto, a maior parte da área estava coberta por sedimentos. A limpeza de cerca de $500 \mathrm{~m}^{2}$ do afloramento rochoso revelou um impressionante conjunto contendo até o momento mais de 70 sulcos de formas variadas, reunidos em sub-conjuntos de acordo com a superfície da rocha suporte (Fig. 1). Acredita-se que ainda existem sulcos soterrados por sedimento no local, e que as dimensões da oficina lítica original provavelmente eram muito maiores. As rochas sobre as quais foram feitos os amoladores-polidores sofreram exploração em período histórico, apresentando marcas de corte e sinais do uso de explosivos. Um pequeno conjunto de sulcos foi observado também na porção mais ao sul do sítio, suge- rindo que amoladores-polidores ocorram em outros pontos do afloramento rochoso sobre o qual o sambaqui está assentado.

Segundo classificação proposta por Tenório (2003a), as formas dos sulcos observados são: canoa, canoa com friso (ocorrendo um único friso ou mais de um), frisos, frisos paralelos e bacias. Em alguns casos observa-se a ocorrência de agrupamentos, como conjuntos de frisos ao redor de bacias, sequências de frisos paralelos e canoas agrupadas (Fig. 1, Fig. 2).

Um levantamento não exaustivo mostra que tais oficinas líticas ocorrem em diversos pontos do litoral, tanto nos estados de Santa Catarina (Tiburtius \& Bigarella 1953; Rohr 1961; Beck 1971; Duarte 1971; Rüthschilling \& Schmitz 1990; Amaral 1995; Fossari 2004) e Rio de Janeiro (Dias Jr 1959; Oliveira \& Ayrosa 1992; Menezes et al. 1999; Tenório 1999, 2003a, 2003b; Tenório et al. 2008), quanto em outros estados (e.g. Perota 1969; Chymz 1971; Calderon 1974; Uchôa 1978/79/80). As duas maiores concentrações de amoladores-polidores fixos conhecidas no litoral brasileiro situam-se na Ilha de Santa Catarina (SC) e na Ilha Grande (RJ) (Amaral 1995; Tenório 2003). Na Ilha Grande, 47 conjuntos de amoladores-polidores

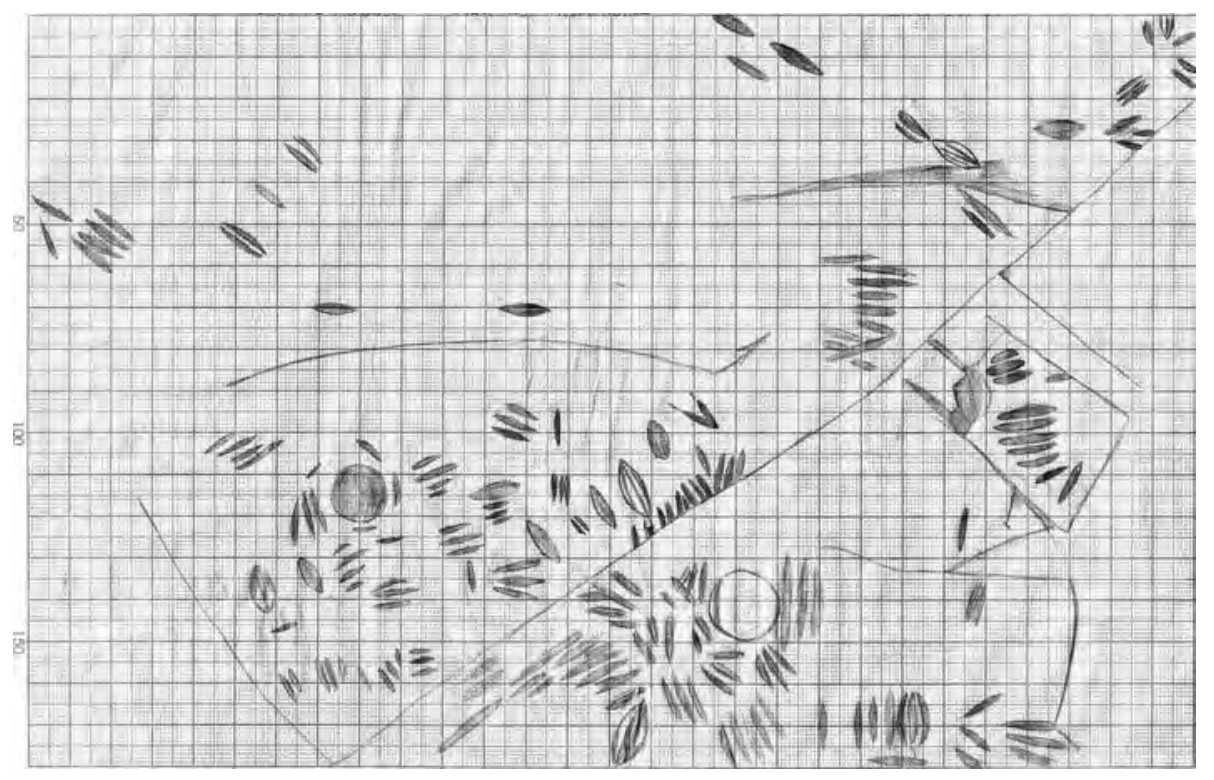

Fig. 1. Croquis à mão livre representando o conjunto de amoladores-polidores evidenciado (desenho: Jorge Ferreira). 

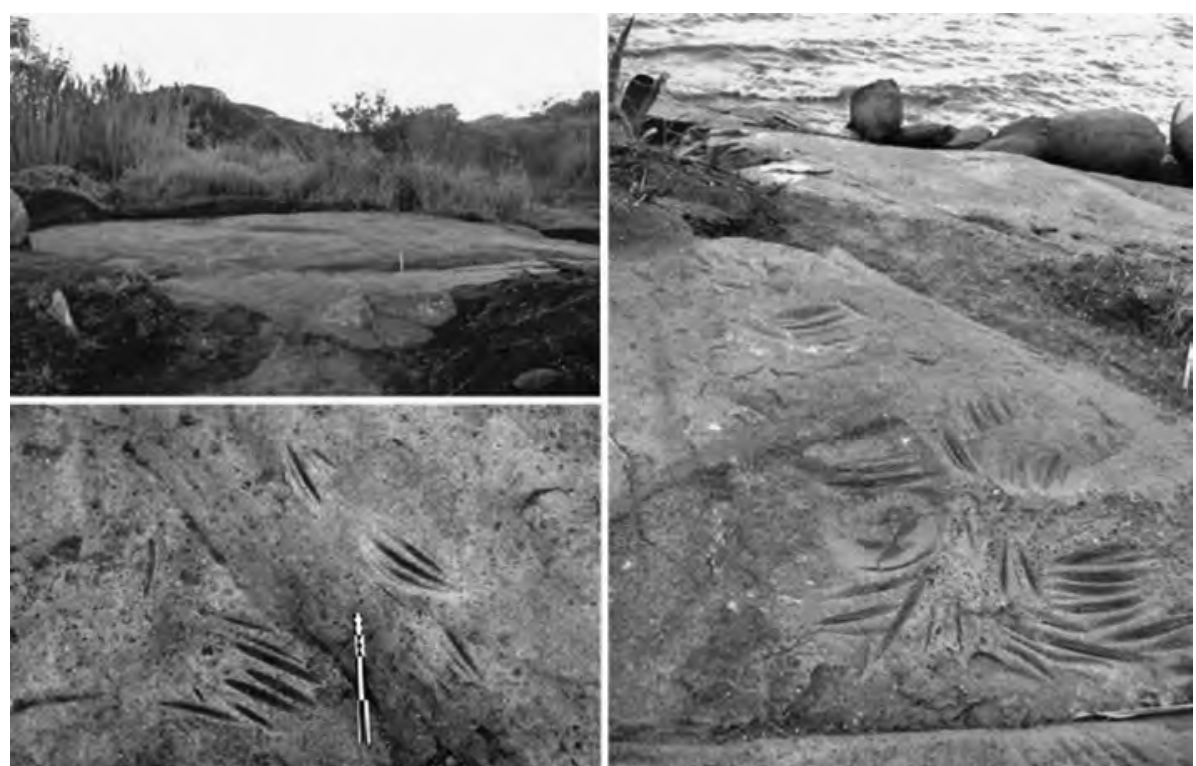

Fig. 2. Aspecto geral do sítio Cabeçuda-II e sua relação espacial com o Sambaqui de Cabeçuda, ao fundo (acima, à esq.) e detalhes dos amoladores-polidores evidenciados.

fixos espalhados em todo seu entorno sugerem a existência de centros de produção e distribuição de lâminas de machado polidas (Tenório 2003).

Diversos autores consideram que estas oficinas líticas não constituem traço cultural que possa ser diretamente associado a grupos socioculturais específicos. Outros propuseram que grupos distintos, ceramistas e não ceramistas, tenham utilizado os mesmos locais para produção de artefatos polidos (Oliveira \& Ayrosa 1992). Em Santa Catarina, estes sítios são frequentemente atribuídos a grupos Jê (Fossari 2004). Gaspar \& Tenório (1990), todavia, propõem uma associação específica destas oficinas com os sambaquis. A partir de um levantamento de 43 sítios com amoladores-polidores de Santa Catarina, as autoras verificaram que $82,3 \%$ dos registros situam-se na proximidade de sambaquis ou de sítios do tipo "acampamentos", e apenas 17,6\% estão próximos a sítios cerâmicos. Esta associação, no entanto, não descarta o desenvolvimento de oficinas líticas por grupos não sambaquieiros, como o proposto por Fossari (2004) ou registrado no interior do estado por Herberts et al. (2007).
No caso presente, a proximidade espacial da oficina lítica com o Sambaqui de Cabeçuda, associada ao grande número de artefatos líticos polidos encontrados neste sítio, muitos deles bastante elaborados, permite sugerir que estas marcas sejam resultado do intenso trabalho realizado pelos construtores do Sambaqui de Cabeçuda. O achado, no sambaqui, de um amolador-polidor portátil sobre suporte de diabásio corrobora esta hipótese. Naturalmente, não é possível descartar o uso posterior do sítio por outros grupos, mas não existe nenhuma evidência arqueológica que aponte para este fato.

Os projetos ora em curso darão continuidade às investigações arqueológicas sobre o Sambaqui de Cabeçuda. Paralelamente, pretende-se expor completamente a estrutura do sítio Cabeçuda-II, além de ampliar as buscas para identificação de outros possíveis conjuntos de amoladores-polidores fixos em áreas próximas.

Pode-se considerar que este conjunto de sítios materializa uma paisagem com forte conteúdo simbólico, reiterando a importância do Sambaqui de Cabeçuda neste sistema de assentamento. Sua preservação e estudo 
se revestem, assim, de ainda maior relevância e são fundamentais para uma melhor compreensão do sistema sambaquieiro.

\section{Agradecimentos}

As ações envolvendo escavação sistemática do sambaqui de Cabeçuda e a evidenciação de Cabeçuda II foram desenvolvidas no âmbito do projeto "Gente, plantas e bichos: uma investigação multidisciplinar sobre o ritual funerário em dois importantes sambaquis do sul de Santa Catarina (Jabuticabeira-II e Cabeçuda)" (Universal CNPq, coord. Rita Scheel-Ybert). Também integram as ações desenvolvidas neste sítio os projetos "Sambaquis e Paisagem" (FAPESP, coord. Paulo DeBlasis), "Revisitando a coleção osteológica humana do Sambaqui de Cabeçuda, SC: recuperação de informações, produção de novos dados e reconstrução de seu potencial informativo" (FAPERJ, coord. Claudia Rodrigues-Carvalho), "Alimento, sacrifício ou oferenda: possíveis usos da fauna do sambaqui de Cabeçuda" (CNPq, coord. Daniela Klökler), e "Sambaquis: médios, grandes e monumentais - Estudo sobre as dimensões dos sítios arqueológicos e seu significado social" (Pronex FAPERJ, coord. MaDu Gaspar). Rita Scheel-Ybert, Claudia Rodrigues-Carvalho e $\mathrm{MaDu}$ Gaspar são pesquisadoras do CNPq.

\section{Referências bibliográficas}

AMARAL, M.M.V.

1995 As oficinas líticas de polimento da Ilha de Santa Catarina. Dissertação de Mestrado. Porto Alegre, Pontífica Universidade Católica.

BECK, A.

1971 Os sambaquis do litoral de Laguna - SC. In: Duarte, P. (Ed.) O Homem Antigo na América. São Paulo, Instituto de Pré-História, USP: 69-76.

CALDERON, V.

1974 Contribuição para o conhecimento da arqueologia do recôncavo e do sul da Bahia. Boletim do Museu Paraense Emílio Goeldi, 26: $141-155$.

CASTRO FARIA, L.

1952 Pesquisas de Antropologia Física no Brasil. Boletim do Museu Nacional, n.s., Antropologia, 13: 1-106.

1955 Le problème des sambaquis du Brésil: recentes excavations du gisement de Cabeçuda (Laguna, Santa Catarina). In: Anais do XXXI Congresso Internacional de Americanistas, São Paulo: 569-577.

1959 O problema da proteção aos sambaquis. Arquivos Museu Nacional, 59: 95-138.

DIAS Jr, O.

1959 Polidores de Cabo Frio. Boletim de História, 4-5 (I-II): $15-20$.

DUARTE, G.M.

1971 Distribuição e localização de sítios arqueológicos tipo sambaqui na Ilha de Santa Catarina. Anais do Museu de Antropologia de Florianópolis, 4: 31-59.

FOSSARI, T.D.

2004 A população pré-colonial Jê na paisagem da ilha de Santa Catarina. Tese de doutorado. Florianópolis, Universidade Federal de Santa Catarina.

GASPAR, M.D.; TENÓRIO, M.C.

1990 Amoladores e polidores fixos do litoral brasileiro. Revista do CEPA, 17 (20): 181190.

GUERRA, A.T.

1950 Contribuição ao estudo da geomorfologia e do quaternário do litoral de Laguna (Santa Catarina). Revista Brasileira de Geografia, 12 (4): 535-564.

HERBERTS, A.N.; LAVINA, R.; COMERLATO, F.; COSTA, C.

2007 Oficinas líticas de polimento no interior de Santa Catarina. In: Anais do V encontro do Núcleo Regional Sul da Sociedade de Arqueologia Brasileira: 1-4.

MENDONCCA DE SOUZA, S.M.

1991 Aplicação de funções discriminantes à estimativa de sexo em ossos humanos pré-históricos. Dissertação de mestrado. Rio de Janeiro, UFRJ.

MENEZES, L.F.; ARAUJO, D.S.D; GOES, M.H.B.

1999 Marambaia, última restinga carioca preservada. Ciência Hoje, 23 (136): 28-37. 
OLIVEIRA, N.V.; AYROSA, P.P.S.

1992 Polidores e Amoladores fixos de Piraquara, Angra dos Reis. In: Anais da VI Reunião Científica da SAB, Rio de Janeiro: $753-760$

ROHR, J.A.

1961 Pesquisas paleoetnográficas na Ilha de Santa Catarina e notícias prévias sobre sambaquis da Ilha de São Francisco do Sul. Pesquisas, 12: 1-18.

RÜTHSCHILLING, A.L.; SCHMITZ. P.I.

1990 O sambaqui da praia das Laranjeiras, Balneário de Camboriú. Revista do CEPA, 17 (20): 191-203.

TENÓRIO, M.C.

1999 Os fabricantes de machado da Ilha Grande. In: Tenório, M.C. (Ed.) Pré-história da Terra Brasilis. Rio de Janeiro, EDUFRJ: 233-246.

2003a O lugar dos Aventureiros: identidade, dinâmica de ocupação e sistema de trocas no litoral do Rio de Janeiro há 3500 anos antes do presente. Tese de Doutorado. Porto Alegre, Pontífica Universidade Católica.

2003b Os amoladores-polidores fixos. Revista de Arqueologia, 16: 87-108.

TENÓRIO, M.C.; PINTO, D.C.; AFONSO, M.C.

2008 Dinâmica de ocupação, contatos e trocas no litoral do Rio de Janeiro no período de 4000 a 2000 anos ap. Arquivos do Museu Nacional, 66 (2): 311-321.

TIBURTIUS, G.; BIGARELLA, I.

1953 Nota sobre os anzóis de osso da jazida paleoetnográfica de Itacoara, Santa Catarina. Revista do Museu Paulista, n.s., 7: 381-387.

UCHÔA, D.P.

1978/ Arcaico do litoral. In: Schmitz, P.; Barbosa,

79/80 A.S.; Ribeiro, M. (Eds.) Temas de Arqueologia Brasileira 3. Goiânia. Instituto Goiano de Pré-História e Antropologia. Anuário de Divulgação Científica, 6: 15-32. 


\section{Revista do Museu de Argueologia e Etnologia da Universidade de São Paulo}

\section{Instruções aos autores}

- Enviar os manuscritos no formato descrito abaixo, acompanhados de carta de solicitação para publicação ao editor, para:

Museu de Arqueologia e Etnologia - USP

Universidade de São Paulo

Av. Prof. Almeida Prado 1466

CEP 05508-900

São Paulo - Brasil

- Os originais devem ser enviados em CDs, até 31 de maio do ano da publicação. Estes deverão ter sido digitados através do processador de textos MS-Word, em equipamento padrão IBM - PC ou compatível. No mesmo CD, um segundo arquivo deverá conter nome, endereço, e-mail, telefone e/ou fax dos autores e, ainda, informações sobre a versão e programa utilizados, caso não tenham sido aqueles aqui indicados. $\mathrm{O}$ material enviado deverá incluir uma cópia impressa e não será devolvido.

- A Revista adota o sistema de "peer review". Todos os artigos são enviados ao nosso corpo de árbitros que recomendará, ou não, sua publicação, podendo também sugerir modificações.

\section{Artigos}

- Os textos (30 páginas no máximo, incluindo tabelas, mapas e ilustrações) podem ser escritos em português, inglês, espanhol, francês ou italiano.

- Serão fornecidas gratuitamente 20 separatas.

\section{Resenhas}

- 5 páginas, no máximo.
Notas

- 4 páginas, no máximo.

\section{Formatação do texto}

- O texto deverá obedecer ao seguinte padrão:

a) Times New Roman, corpo 12; espaço 1,5; margens esquerda e direita: $3 \mathrm{~cm}$; margens superior e inferior: $2,5 \mathrm{~cm}$.

b) Artigos: a primeira folha deverá conter: 1) título (português e inglês); 2) nome dos autores, instituições a que pertencem e respectivos emails e endereço completo; 3) um resumo bilingue (inglês/português) de, no máximo, 10 linhas, contendo objetivos, metodologia e resultados; 4) palavras-chave, inglês/português).

c) As figuras devem ser enviadas em mídia eletrônica em formato jpeg ou tiff, com resolução mínima de 300 dpi. Na elaboração das figuras, gráficos, tabelas, e fotografias (estas somente em branco e preto) devem-se levar em conta as dimensões úteis da Revista $(18 \times 27 \mathrm{~cm})$ a fim de que, no caso de redução, não se tornem ilegíveis; este material deve ser enviado juntamente com o CD, devidamente acondicionado.

d) Escalas gráficas deverão ser sempre utilizadas em lugar de escalas numéricas.

e) As notas de rodapé, numeradas na ordem em que aparecem no texto, devem estar situadas no final do arquivo, juntamente com os agradecimentos, apêndices, legendas das figuras e tabelas.

f) As notas de rodapé não deverão conter referências bibliográficas. Estas deverão ser inseridas no próprio texto, entre parênteses, remetendo o leitor à bibliografia. Ex.: (Renfrew 2003: 115-155).

g) A bibliografia seguirá a ordem alfabética pelo sobrenome do autor citado em primeiro lugar. 


\section{Exemplos:}

Artigos em periódicos:

BOCQUET, A.

1979 Lake bottom archaeology. Scientific American, 240 (2): 56-75.

Capítulos de livros:

FOLEY, R. A.

1981 Off site archaeology: an alternative approach for the short sites. In:
Hodder, I.; Isaac, G.; Hammond, N. (Eds.) Pattern of the Past Studies in Honor of David L. Clarke. Cambridge, Cambridge University Press: 157-183.

Livros:

SANOJA, M.; VARGAS, I.

1978 Antigas formaciones y modos de producci venezolanos. Caracas: Monte Avila Editores. 